\title{
Weight loss improves disease activity in patients with psoriatic arthritis and obesity: an interventional study
}

Eva Klingberg ${ }^{1 *}$ D, Annelie Bilberg ${ }^{2}$, Sofia Björkman ${ }^{3}$, Martin Hedberg ${ }^{4}$, Lennart Jacobsson', Helena Forsblad-d'Elia ${ }^{1,5}$, Hans Carlsten ${ }^{1}$, Björn Eliasson ${ }^{6}$ and Ingrid Larsson ${ }^{3}$

\begin{abstract}
Background: Obesity is over-represented in patients with psoriatic arthritis (PSA) and associated with higher disease activity, poorer effect of treatment and increased cardiovascular morbidity. Studies on the effects of weight loss are however needed. This study aimed to prospectively study the effects of weight loss treatment with very low energy diet (VLED) on disease activity in patients with PSA (CASPAR criteria) and obesity (body mass index BMl $\geq 33 \mathrm{~kg} / \mathrm{m}^{2}$ ).

Methods: VLED (640 kcal/day) was taken during 12-16 weeks, depending on pre-treatment BMI. Afterwards, an energy-restricted diet was gradually reintroduced. Weight loss treatment was given within a structured framework for support and medical follow-up.

Treatment with conventional synthetic and/or biologic disease-modifying anti-rheumatic drugs was held constant from 3 months before, until 6 months after baseline.

Patients were assessed with BMl, 66/68 joints count, Leeds enthesitis index, psoriasis body surface area (BSA), questionnaires and CRP at baseline, 3 and 6 months. Primary outcome was the percentage of patients reaching minimal disease activity (MDA) and secondary outcomes were reaching Psoriatic Arthritis Response Criteria (PsARC) and American College of Rheumatology (ACR) response criteria.
\end{abstract}

Results: Totally 41/46 patients completed the study, 63\% women, median age 54 years (IQR 48-62). At baseline increased BMI was associated with higher disease activity and poorer function.

The median weight loss was $18.7 \mathrm{~kg}$ (IQR 14.6-26.5) or 18.6\% (IQR 14.7-26.3) of the baseline weight. A majority of the disease activity parameters improved significantly after weight loss, including 68/66 tender/swollen joints count, CRP, BSA, Leeds enthesitis index, HAQ and patient VAS for global health, pain and fatigue. A larger weight loss resulted in more improvement in a dose-response manner. The percentage of patients with MDA increased from 29 to 54\%, ( $p=0.002)$. PSARC was reached by $46.3 \%$. The ACR 20, 50 and 70 responses were $51.2 \%, 34.1 \%$ and $7.3 \%$ respectively.

Conclusions: Short-term weight loss treatment with VLED was associated with significant positive effects on disease activity in joints, entheses and skin in patients with PSA and obesity. The study supports the hypothesis of obesity as a promotor of disease activity in PsA.

Trial registration: ClinicalTrials.gov identifier: NCT02917434, registered on September 21, 2016-retrospectively registered Keywords: Psoriatic arthritis, Psoriasis, Obesity, Metabolic syndrome, Weight loss, VLED, Cardiovascular disease

\footnotetext{
* Correspondence: eva.klingberg@vgregion.se

${ }^{1}$ Department of Rheumatology and Inflammation Research, Sahlgrenska

Academy at the University of Gothenburg, Gothenburg, Sweden

Full list of author information is available at the end of the article
}

(c) The Author(s). 2019 Open Access This article is distributed under the terms of the Creative Commons Attribution 4.0 International License (http://creativecommons.org/licenses/by/4.0/), which permits unrestricted use, distribution, and reproduction in any medium, provided you give appropriate credit to the original author(s) and the source, provide a link to the Creative Commons license, and indicate if changes were made. The Creative Commons Public Domain Dedication waiver (http://creativecommons.org/publicdomain/zero/1.0/) applies to the data made available in this article, unless otherwise stated. 


\section{Background}

Psoriasis affects $2-3 \%$ of the population in Sweden and $20-30 \%$ of individuals with psoriasis develop psoriatic arthritis (PsA), a chronic rheumatic disease leading to synovitis, enthesitis and sometimes also axial involvement [1]. Both psoriasis and PsA are strongly associated with obesity and the metabolic syndrome (MetS) [2]. International observational studies have reported prevalence of obesity (body mass index (BMI) $\geq 30 \mathrm{~kg} / \mathrm{m}^{2}$ ) in $45 \%$ of PsA patients and of MetS in 30-45\% [3-5]. Previous studies have shown that obesity increases the risk of developing both psoriasis and PsA and that obesity is associated with higher disease activity, poorer treatment response and lower chance of achieving minimal disease activity (MDA) [3, 6-10]. Patients with PsA also have an increased risk of cardiovascular disease (CVD) [11-13]. Chronic inflammation, which accelerates the atherosclerotic process, in combination with higher prevalence of cardiovascular $(\mathrm{CV})$ risk factors among PsA patients is believed to contribute to this increased risk [14-16].

Although the associations between PsA and obesity, BMI and disease activity are well known, there is to the best of our knowledge only one prior interventional study which has prospectively assessed the effects of weight loss treatment in PsA [17].

The aim of this study was to determine the effects of weight loss treatment with very low energy diet (VLED) on the disease activity in joints, entheses and skin in patients with PsA and obesity. The primary endpoint of the study was the percentage of patients reaching minimal disease activity (MDA) after 6 months weight loss treatment. Secondary endpoints were the percentage of patients reaching American College of Rheumatology (ACR) and Psoriatic Arthritis Response Criteria (PsARC).

\section{Patients and methods Patients}

Patients with PsA and obesity registered at the Rheumatology clinics of Sahlgrenska University hospital and the hospitals of Alingsås and Borås were invited to participate.

Patients with PsA fulfilling the Classification for Psoriatic Arthritis (CASPAR) criteria, with a $\mathrm{BMI} \geq 33 \mathrm{~kg} / \mathrm{m}^{2}$ and age 25-75 years were eligible for inclusion [18]. If using conventional synthetic and/or biologic disease-modifying anti-rheumatic drugs (cs and/or bDMARDs), the treatment had to be constant and unchanged from 3 months prior to baseline until 6 months after baseline. Exclusion criteria were pregnancy, porphyria, epilepsy, type 1 diabetes, severe heart, kidney or catabolic disease, binge eating disorders, treatment with warfarin, lithionin or phenantoin, mental imbalance affecting participation, being subject to a heart infarction, stroke, major surgery or trauma during last the
3 months and being treated for cancer during the last 5 years.

All the patients in the study gave their written informed consent. The study was approved by the Regional Ethics Committee in Gothenburg and carried out in accordance with the Helsinki Declaration.

\section{Intervention: weight loss treatment with very low energy diet (VLED)}

Weight loss treatment with VLED $(<800 \mathrm{kcal} /$ day $)$ is an effective and established method in clinical use in Sweden. In severe obesity, BMI $\geq 35.0 \mathrm{~kg} / \mathrm{m}^{2}$, a rigorous energy restriction is needed for optimal weight loss [19]. The VLED used in the present study provided a daily intake of $640 \mathrm{kcal}$ including recommended doses of vitamins, minerals and other essential nutrients (Cambridge Weight Plan Limited, Corby, UK). The diet consisted of four daily portions of powder dissolved in cold or hot water and consumed as shakes or soups. Based on pre-treatment BMI $\left(<40\right.$ or $\left.\geq 40 \mathrm{~kg} / \mathrm{m}^{2}\right)$, the participants followed an initial period of 12 or 16 weeks on strict VLED. In addition, non-energy-containing beverages were allowed at libitum. During VLED, the mean weight loss usually is $1-2 \mathrm{~kg}$ per week. Adherence to treatment was controlled by measuring the body weight of the patients regularly. Absent or limited weight loss was considered a sign of poor adherence to the diet.

After the strict period, food was gradually reintroduced during a period of 12 weeks. Each patient was instructed to follow an energy-restricted diet based on individual energy requirements for weight stability reduced by $30 \%$ to achieve further weight loss. The side effects of the VLED treatment are mostly mild to moderate and transient and ceases when the strict period is ended. The most prevalent side effects are headache, nausea, obstipation, dryness of skin and hair loss [19]. The treatment is not associated with any health risks, when given under the surveillance of health professionals following an evidence-based protocol $[19,20]$. The treatment was given within the framework of a 12-month protocol including structured weight loss treatment, support and medical follow-up from a team of doctors, nurses and dieticians at the Obesity Unit at Sahlgrenska University Hospital.

\section{Measures of assessment}

All examinations were done at baseline, after 3 months and 6 months. No blinding of assessors was made. Body height and weight were measured with a calibrated ruler and digital scale. Waist circumference was measured with a tape measure in centimetres midway between the lower rib and iliac crest. Joints were examined with 66/ 68 swollen/tender joints count and entheses with Leeds enthesitis index [21]. The extent of psoriasis was evaluated with body surface area (BSA) [22]. Quality of life 
related to psoriasis was assessed with the Dermatology Life Quality Index (DLQI) [23]. The patients' disease activity was assessed with visual analogue scales (VAS) for global disease activity, pain and fatigue. The physician's global assessment of disease activity was also evaluated with a VAS. Function and activity limitations were assessed using the Health Assessment Questionnaire (HAQ) [24]. Both the Disease Activity Score using 28 joint counts based on CRP (DAS28CRP) and the Disease Activity in PSoriatic Arthritis (DAPSA) score were calculated $[25,26]$.

The primary endpoint minimal disease activity (MDA) is defined as meeting five of the seven following criteria: tender joint count $68 \leq 1$, swollen joint count $66 \leq 1$, psoriasis body surface area $\leq 3 \%$, patient pain VAS $\leq 15$ $\mathrm{mm}$, patient global disease activity VAS $\leq 20 \mathrm{~mm}$, HAQ $\leq 0.5$ and tender entheseal points $\leq 1$ [27].

Secondary endpoints were the number of patients reaching the PsA Response Criteria (PsARC) and the American College of Rheumatology (ACR) 20, 50 and 70 criteria for treatment response. The PsARC is defined as improvement in at least two of the following four areas: $\geq 20 \%$ improvement in physician's global VAS, $\geq 20 \%$ improvement in patient global disease activity VAS, $\geq 30 \%$ improvement in 66 swollen joint count, $\geq 30 \%$ improvement in 68 tender joint count. Improvement in the swollen or tender joint counts is mandatory, and there should be no worsening of any component $[28,29]$. The ACR 20,50 and 70 criteria are defined as a $20 \%, 50 \%$ or $70 \%$ improvement in the 28 swollen or tender joint counts together with a $20 \%, 50 \%$ or $70 \%$ improvement in at least 3/5 of the following: the patient's global health VAS, patient's pain VAS, physician's global VAS, HAQ and CRP or ESR [30].

Blood samples were analysed for haemoglobin $(\mathrm{Hb})$, white blood cell count (WBC), platelet count (PLT) and C-reactive protein (CRP) using standard laboratory techniques at Sahlgrenska University Hospital.

\section{Statistical analyses}

Statistical analyses were made using SPSS Statistics version 25 (IBM, Chicago, USA). Descriptive statistics are presented as median and interquartile range (IQR) and range. Wilcoxon signed rank test was used to compare continuous related samples and McNemar test to compare categorical related samples. Correlations were calculated using Spearman's correlation $\left(r_{\mathrm{S}}\right)$. All tests were two-tailed, and $p \leq 0.05$ was considered statistically significant.

\section{Results}

Characteristics of the study population

In total, 46 patients were included and started VLED treatment, whereof five patients (11\%) dropped out before the 6 months visit (at the beginning of the VLED treatment, one cancelled participation and one was excluded due to depression, after 3 months two cancelled participation and one was excluded due to pregnancy).

A total of 41 patients completed the study, 63\% women. The median baseline age was 54 (IQR 48-62) years. The characteristics of the study population are shown in Table 1.

\section{The association between BMI and disease activity at baseline}

At baseline BMI was positively correlated with several measures of disease activity and function including DAS28CRP, DAPSA, tender joints count, CRP, patient's global health VAS, Leeds enthesitis index and HAQ (Spearman's rho ranged from $r_{\mathrm{S}}=0.312, p=0.047$ to $r_{\mathrm{S}}$ $=0.483, p=0.001)($ Table 2$)$.

Table 1 Characteristics of the 41 patients with PsA and obesity included in the study

\begin{tabular}{|c|c|}
\hline & Number (\%) or median (IQR) \\
\hline Sex women/men, $n$ (\%) & $26(63.4) / 15(36.6)$ \\
\hline Age, years & $54(48.5-62)$ \\
\hline Duration of psoriasis, years & $32(19-40)$ \\
\hline \multirow{3}{*}{$\begin{array}{r}\text { Duration of PsA symptoms, years } \\
\text { PsA type, } n(\%) \\
\text { Peripheral disease }\end{array}$} & $17(11-27)$ \\
\hline & \\
\hline & \\
\hline \multirow{2}{*}{ Axial disease } & \\
\hline & $2(5)$ \\
\hline \multirow[t]{2}{*}{ Combination peripheral/axial } & \\
\hline & $4(10)$ \\
\hline History of dactylitis, $n$ (\%) & $21(51)$ \\
\hline History of anterior uveitis, $n$ (\%) & $3(7)$ \\
\hline NSAIDs, $n(\%)$ & $27(66)$ \\
\hline TNFi all, $n(\%)$ & $15(37)$ \\
\hline TNFi in monotherapy & 4 \\
\hline TNFi + csDMARD & 11 \\
\hline Ustekinumab monotherapy, $n$ (\%) & $1(2.4)$ \\
\hline csDMARD without biologic, $n(\%)$ & $19(46)$ \\
\hline Methotrexate & 13 \\
\hline Sulfasalazine & 2 \\
\hline Apremilast & 1 \\
\hline Methotrexate + sulfasalazine & 3 \\
\hline Anti-hypertensives, $n$ (\%) & $18(44)$ \\
\hline Lipid lowering therapy, $n$ (\%) & $6(15)$ \\
\hline Oral anti-diabetics, $n$ (\%) & $1(2.4)$ \\
\hline
\end{tabular}

cSDMARD conventional synthetic disease modifying anti-rheumatic drug, NSAID non-steroidal anti-inflammatory drug, TNFi tumour necrosis factor inhibitor 
Table 2 The correlation between BMI and disease activity and function at baseline in patients with PsA and obesity $(N=41)$

\begin{tabular}{lll}
\hline & Spearman's rho & $p$ value \\
\hline CRP, mg/L & 0.312 & 0.047 \\
Tender joints 68, score & 0.333 & 0.034 \\
Swollen joints 66, score & -0.139 & 0.385 \\
VAS patients global disease activity, mm & 0.370 & 0.017 \\
VAS pain, mm & 0.298 & 0.059 \\
VAS fatigue, mm & 0.220 & 0.168 \\
DAS28CRP, score & 0.382 & 0.014 \\
DAPSA, score & 0.360 & 0.021 \\
Leeds enthesitis index, score & 0.483 & 0.001 \\
BSA, \% & -0.155 & 0.334 \\
HAQ, score & 0.457 & 0.003 \\
DLQI, score & -0.113 & 0.483 \\
\hline
\end{tabular}

$B M I$ body mass index, BSA body surface area, CRP C-reactive protein, DAPSA Disease Activity in PSoriatic Arthritis, DAS28CRP Disease Activity Score using 28 joint counts based on CRP, DLQI Dermatology Life Quality Index, VAS visual analogue scale

\section{Weight loss and waist circumference}

All the patients lost weight, from a minimum of 8.5 to a maximum of $40.2 \mathrm{~kg}$. The median weight loss from baseline to the 6 months visit was $18.7 \mathrm{~kg}$ (IQR 14.6-26.5), corresponding to a loss of in median 18.6\% (IQR 14.726.3) or min-max range $8-35 \%$ of baseline weight. BMI decreased from median $35.2 \mathrm{~kg} / \mathrm{m}^{2}$ (IQR $34.1-38.1$ ) to $29.7 \mathrm{~kg} / \mathrm{m}^{2}$ (IQR 26.2-31.5) $(p<0.001)$ and waistline circumference was reduced from median $116 \mathrm{~cm}$ (IQR $112-122)$ to $95.5 \mathrm{~cm}(89-103)(p<0.001)$.

\section{Change in disease activity}

A significant reduction was seen in a majority of the disease activity measures at the 6 months visit (Table 3). The percentage of patients with MDA (primary endpoint) increased from $29.3 \%(n=12)$ at baseline to $53.7 \%$ $(n=22)$ at 6 months $(p=0.002)$. Regarding the secondary endpoints, PSARC was reached by $46.3 \%(n=19)$ of the patients and ACR 20, 50 and 70 responses by $51.2 \%(n=$ $21), 34.1 \%(n=14)$ and $7.3 \%(n=3)$ respectively (Fig. 1$)$.

The distributions of BSA, DAS28CRP, DAPSA and HAQ at baseline and the three- and six-months visits are shown in Fig. 2. The improvement of the skin occurred later than for the other disease activity parameters. Five patients (12\%) experienced a flare in their psoriatic lesions at the 3 months visit. Six patients (15\%) had a worsening of joint disease defined as an increase in DAPSA score (range +1.9-9.1) at the 6 months visit. The laboratory parameters haemoglobin, CRP and PLT all declined significantly, compared with baseline.

A sub-analysis on the 29 patients who did not already have MDA at baseline, showed that PsARC was reached by $51.7 \%(n=14)$ and ACR 20,50 and 70 response by
62.1\% $(n=18), 37.9 \%(n=11)$ and $6.9 \%(n=2)$ respectively of patients in this group. Disease activity and function before and after weight loss treatment in patients who did not have MDA at baseline is displayed in Additional file 1: Table S1.

\section{Improvement of disease activity in relation to grade of weight loss}

The weight loss in percentage of baseline weight was positively correlated with $\Delta$-DAS28CRP $\left(r_{\mathrm{S}}=0.464 ; p=\right.$ $0.002)$ and $\Delta$-HAQ $\left(r_{\mathrm{S}}=0.376 ; p=0.015\right)$, but not with other $\Delta$-values of disease activity. In addition, the ACR 20 response rate was significantly higher in patients with a weight loss $\geq$ median $18.6 \%(n=21)$ compared with $<$ $18.6 \%(n=20)$ (ACR $2071 \%$ vs 30\%; $p=0.008$ ). Similarly, a trend towards higher ACR 50 response rate was observed in patients with a weight loss $\geq 18.6 \%$ compared with < 18.6\% (ACR $5048 \%$ vs 20\%; $p=0.062$ ). The percentage reduction in waist circumference was also significantly correlated with the reduction in DAS28CRP $(\Delta$-value $)\left(r_{\mathrm{S}}=0.374 ; p=0.019\right)$.

\section{Side effects and the patients' experiences of the VLED treatment}

The treatment was generally well tolerated. Some patients experienced obstipation, freezing, loss of hair and hypotension during the strict VLED period and $12 \%$ a flare in psoriasis as previously mentioned. No serious adverse events occurred. When asked to score their experience of the VLED treatment between 1 (very easy to implement) and 10 (very hard to implement), the median score was 2 (IQR 1-3.5). When asked to score their experience of the VLED treatment in comparison to what they had expected, $83 \%(n=34)$ answered "much easier than expected" or "easier than expected". The patients generally scored their experience of the transition from VLED to normal food as harder. The median score was 4 (IQR 2-6) and totally $56 \%(n=23)$ answered "as expected" or "harder than expected" (Fig. 3).

\section{Discussion}

This study aimed to prospectively investigate the association between VLED weight loss treatment and disease activity in patients with PsA and obesity. We found significant improvement of the disease activity in joints, entheses and skin, reduction of CRP, PLT and parameters assessing function at the 6 months follow-up. The primary endpoint, patients with MDA, increased from $29.3 \%$ at baseline to $53.7 \%$ at 6 months $(p=0.002)$. PSARC was reached by $46 \%$ of the patients, and the ACR 20, 50 and 70 responses were $51 \%, 34 \%$ and $7 \%$ respectively. As a comparison, randomized controlled trials of TNF inhibitors on PsA have typically reported ACR 20 and 50 responses of $50-60 \%$ and $30-40 \%$ 
Table 3 Disease activity and function before and after weight loss treatment in 41 patients with PsA

\begin{tabular}{|c|c|c|c|}
\hline & $\begin{array}{l}\text { Baseline } \\
\text { Median (IQR) } \\
\text { Min-max }\end{array}$ & $\begin{array}{l}6 \text { months } \\
\text { Median (IQR) } \\
\text { Min-max }\end{array}$ & $p$ value \\
\hline Weight, kg & $\begin{array}{l}106.3(95.8-113.6) \\
84-124\end{array}$ & $\begin{array}{l}82.9(76.4-92.1) \\
61.3-107.4\end{array}$ & $<0.001$ \\
\hline $\mathrm{BMI}, \mathrm{kg} / \mathrm{m}^{2}$ & $\begin{array}{l}35.2(34.1-38.1) \\
33.0-45.8\end{array}$ & $\begin{array}{l}29.8(26.6-31.5) \\
23.1-37.0\end{array}$ & $<0.001$ \\
\hline Waist circumference, cm & $\begin{array}{l}116(112-122) \\
103-135\end{array}$ & $\begin{array}{l}95.5(89-103) \\
81-116\end{array}$ & $<0.001$ \\
\hline$C R P, \mathrm{mg} / \mathrm{L}$ & $\begin{array}{l}4(2-8.5) \\
1-50\end{array}$ & $\begin{array}{l}2(1-6.5) \\
1-50\end{array}$ & 0.041 \\
\hline Hemoglobin, g/L & $\begin{array}{l}144(132-150) \\
116-179\end{array}$ & $\begin{array}{l}141(131.5-148) \\
118-161\end{array}$ & 0.047 \\
\hline WBC, $10^{9} / \mathrm{L}$ & $\begin{array}{l}5.9(5.2-7.6) \\
4.3-15.2\end{array}$ & $\begin{array}{l}5.9(5.0-6.8) \\
(3.2-12.7)\end{array}$ & 0.062 \\
\hline $\mathrm{PLT}, 10^{9} / \mathrm{L}$ & $\begin{array}{l}270(204-300) \\
174-444\end{array}$ & $\begin{array}{l}230(186-290) \\
156-402\end{array}$ & $<0.001$ \\
\hline Tender joints 68 , score & $\begin{array}{l}4(1-14) \\
0-30\end{array}$ & $\begin{array}{l}2(0-6.5) \\
0-19\end{array}$ & $<0.001$ \\
\hline Swollen joints 66 , score & $\begin{array}{l}0(0-1) \\
0-5\end{array}$ & $\begin{array}{l}0(0-0.5) \\
0-7\end{array}$ & 0.021 \\
\hline VAS patients global disease activity, mm & $\begin{array}{l}34(19-61) \\
0-93\end{array}$ & $\begin{array}{l}12(5-51) \\
0-95\end{array}$ & 0.001 \\
\hline VAS pain, mm & $\begin{array}{l}30(18.5-62.5) \\
0-95\end{array}$ & $\begin{array}{l}20(5-51.5) \\
0-95\end{array}$ & 0.004 \\
\hline VAS fatigue, $\mathrm{mm}$ & $\begin{array}{l}56(21.5-67) \\
0-94\end{array}$ & $\begin{array}{l}25(8-44) \\
0-98\end{array}$ & 0.001 \\
\hline DAS28CRP, score & $\begin{array}{l}2.9(2.1-3.7) \\
1.4-5.6\end{array}$ & $\begin{array}{l}2.4(1.7-3.0) \\
1.2-4.5\end{array}$ & $<0.001$ \\
\hline DAPSA, score & $\begin{array}{l}15.3(6.6-29.1) \\
0.9-46\end{array}$ & $\begin{array}{l}11.0(2.8-17.6) \\
0.2-35\end{array}$ & $<0.001$ \\
\hline Leeds enthesitis index & $\begin{array}{l}1(0-4) \\
0-6\end{array}$ & $\begin{array}{l}0(0-3) \\
0-4\end{array}$ & 0.001 \\
\hline $\mathrm{BSA}, \%$ & $\begin{array}{l}1.6(0-2.2) \\
0-10\end{array}$ & $\begin{array}{l}0.9(0-1.1) \\
0-5.5\end{array}$ & 0.014 \\
\hline $\mathrm{HAQ}$, score & $\begin{array}{l}0.70(0.13-1.00) \\
0-2.63\end{array}$ & $\begin{array}{l}0.43(0-0.69) \\
0-1.88\end{array}$ & $<0.001$ \\
\hline DLQI, score & $\begin{array}{l}1(0-4.5) \\
0-17\end{array}$ & $\begin{array}{l}1(0-4) \\
0-20\end{array}$ & 0.453 \\
\hline
\end{tabular}

$B M I$ body mass index, BSA body surface area, CRP C-reactive protein, DAPSA Disease Activity in PSoriatic Arthritis, DAS28CRP Disease Activity Score using 28 joint counts based on CRP, DLQI Dermatology Life Quality Index, PLT platelet count, WBC white blood cell count

respectively, whereas the reported ACR 20 and 50 responses to placebo have been $15-25 \%$ and $0-5 \%$ [31, 32]. Reduction in weight correlated in a dose-response manner with higher ACR 20 response rate and greater reductions in DAS28CRP and HAQ. The treatment which resulted in a substantial weight loss of in median $18.6 \%$ of the baseline weight was well tolerated with only few and mild side effects and was perceived as feasible by a majority of the patients. Further, we found that a higher BMI at baseline was associated with increased disease activity and poorer self-reported function. The present study thus supports the hypothesis that obesity is a promotor of disease activity in PsA.
The mechanisms linking PsA occurrence and disease activity with obesity has not been fully clarified. Both immunological, biomechanical and behavioural mechanisms are likely to be involved in the interplay between PsA and obesity. PsA, obesity and atherosclerosis are conditions characterized by chronic inflammation, mediated via partly common immunologic pathways. Tumour necrosis factor $\alpha$ (TNF $\alpha$ ), interleukin (IL)23, IL17, IL6 and IL1 $\beta$ are all key cytokines in the pathogenesis of PsA. The white adipose tissue (WAT) can produce the same cytokines (TNFo, IL-23, IL-17, IL-6, IL-1 $\beta$ ) in addition to both pro-inflammatory adipokines (resistin, fetuin-A, chemerin, leptin) and adipokines viewed as primarily anti-inflammatory (adiponektin, 


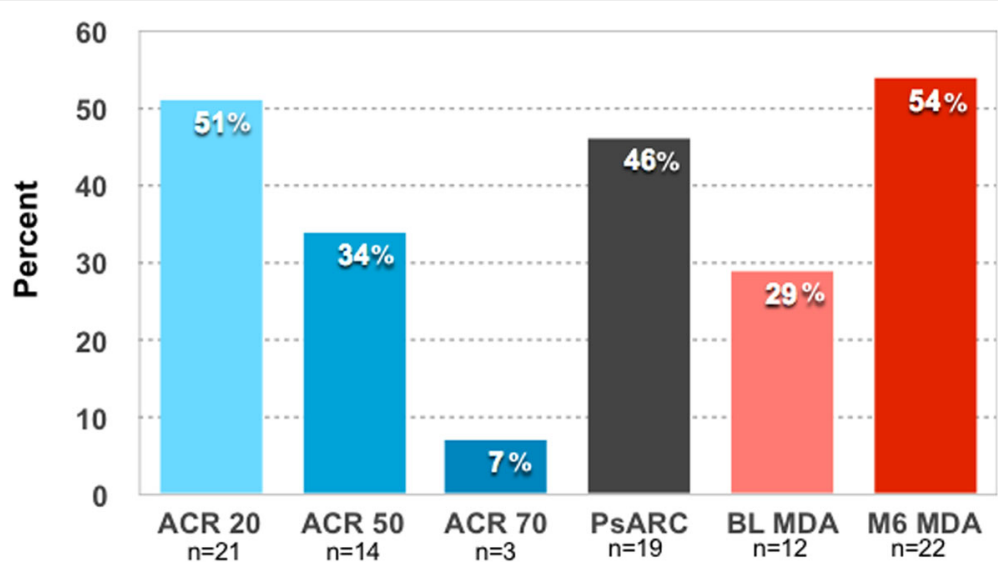

Fig. 1 The percentage of patients reaching American College of Rheumatology (ACR) 20, ACR 50 and ACR 70 response criteria, Psoriatic Arthritis Response Criteria (PsARC) and Minimal Disease Activity (MDA). BL, baseline; M6, 6 months visit

omentin) [33]. In obese individuals, WAT is infiltrated by immune cells, such as M1-type macrophages, dendritic cells, IL17 producing T-lymphocytes (Th17) and B-lymphocytes [34]. Moreover, in obesity, there is a persistent over-production of the pro-inflammatory cytokines and adipokines, which may fuel the autoimmune inflammation in PsA [34, 35]. Interestingly, there is also evidence that localized inflammation in fat pads inside joints, juxta-posed to entheses and underneath psoriatic skin lesions may play a local pathophysiological role in PsA and psoriasis [36]. Elevated levels of leptin and resistin and lower levels of adiponectin in serum adjusted for BMI have been shown in patients with PsA and psoriasis in comparison with healthy controls. Elevated serum leptin and resistin have also been associated with an increased burden of skin and joint inflammation [37, 38].

Biomechanical stress may be another factor linking obesity with PsA. PsA is characterized by enthesitis, which is a chronic inflammation at attachment sites of tendons and ligaments, anatomical locations often subject to mechanical stress [39]. The weight load of obesity leads to both increased mechanical stress and risk of local microdamage. In the general population, obesity is also associated with pathology of entheses and tendons, in both upper and lower extremities [40]. In PsA, repeated occupational lifting of heavy loads and exposure to injury or bone fracture has been associated with onset of inflammatory arthritis in subjects with psoriasis [41, 42]. Psoriasis is also known to develop at sites of trauma, the so-called Köbner response [43]. Studies on animal models for spondyloarthritis (TNF ${ }^{\triangle \mathrm{ARE}}$ and $\mathrm{DBA} / 1$ mice) have provided further proof for the importance of mechanical stress, by showing that unloading of the hind limb or tail suspension prohibited enthesitis and new bone formation in these mice [44].

Behavioural factors can also be a link between PsA and obesity. Pain and skin disease can induce a vicious cycle of lowered physical activity and over-eating, leading to obesity and further reduction of the mobility and physical activity $[8,45]$. Efficient weight loss treatment could help reverse this process. Patients with PsA are at increased risk of developing $\mathrm{CV}$ and thromboembolic disease $[12,13]$. In addition, obesity has been shown to be associated with poorer response and adherence to TNF inhibitor therapy $[17,46]$. We recommend that weight loss treatment should be considered as complementary to pharmacological treatment in patients with PsA and obesity, since weight loss may improve both disease activity, effect of drug treatment and $\mathrm{CV}$ risk profile.

The reduced disease activity seen in the PsA patients after the VLED treatment in the present study could be due to a combination of mechanisms: metabolic effects associated with dietary energy restriction, reduction of pro-inflammatory mediators produced by the WAT, reduced loading of joints and entheses, especially in the back and lower limbs and reduced pain sensitivity. In situations of negative energy balance cells switch to utilize non-hepatic glucose, ketone bodies and free fatty acids as energy source [47]. This has a dampening and pro-apoptotic effect on activated $\mathrm{T}$ lymphocytes, which primarily depend on aerobic glycolysis [48]. Energy restriction and weight loss is also associated with increased levels of glucocorticoids and adiponectin and reduced levels of IL-6, TNF $\alpha$ and leptin in serum $[49,50]$. In the current study, a negative energy balance was mainly present during the 12-16 weeks of strict VLED treatment. After this time point, only six patients (15\%) had a further weight loss, whereas the rest of the patients had an increase in weight between the 3 and 6 months visits, indicative of a positive energy balance. The patients will be followed for 2 years to determine the relation between BMI and disease activity when the patients are no longer in a hypocaloric condition. 

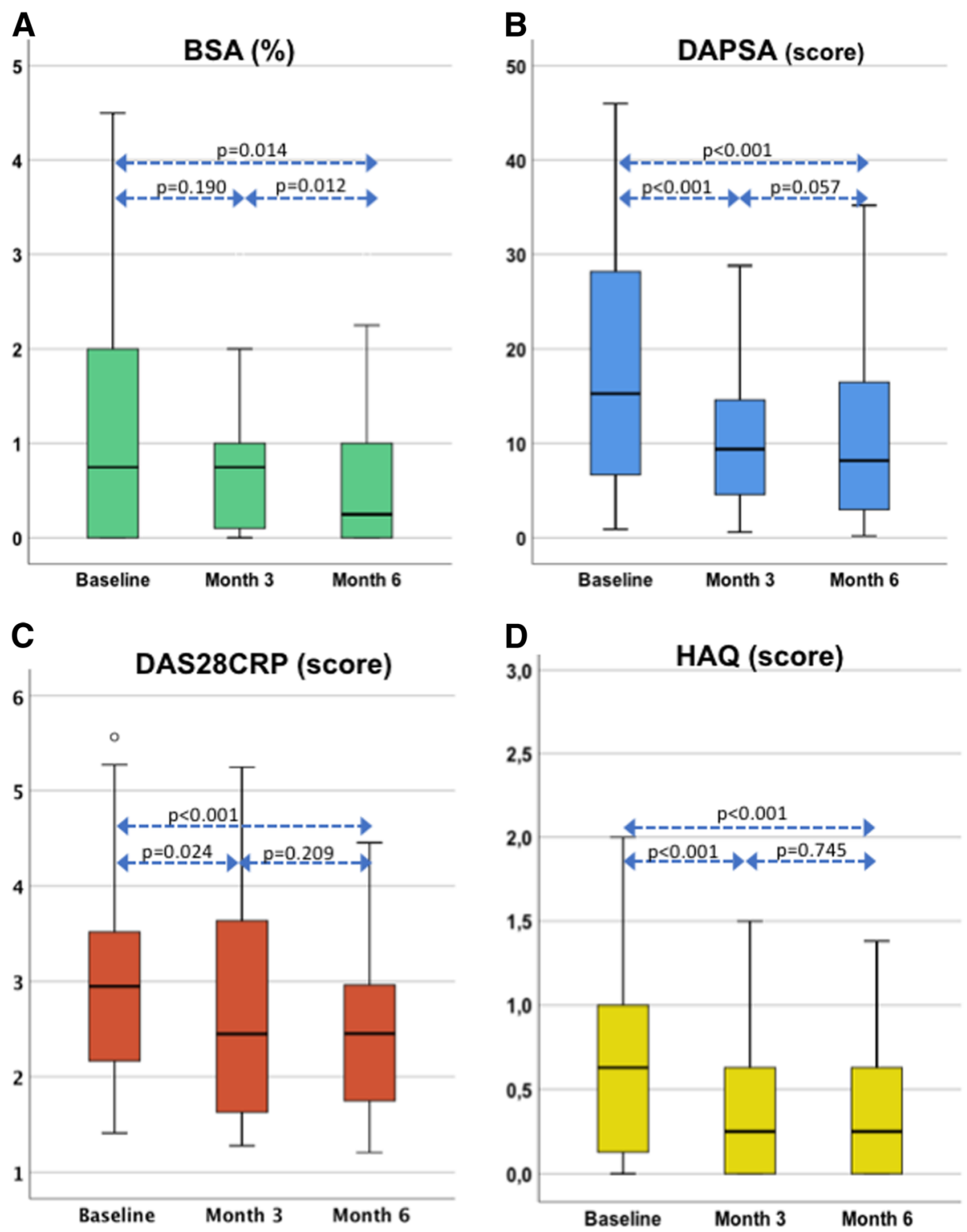

Fig. 2 Boxplots showing the distributions at baseline and the 3 and 6 months visits of a psoriatic body surface area (BSA), b Disease Activity in PSoriatic Arthritis (DAPSA), c Disease Activity Score using 28 joint counts based on CRP (DAS28CRP) and $\mathbf{d}$ Health Assessment Questionnaire (HAQ)

Obesity is associated with increased pain sensitivity in inflammatory rheumatic diseases, osteoarthritis and fibromyalgia [45]. In the current study, the change in composite scores for disease activity after weight loss was mainly driven by a reduction in the number of tender joints and entheses and by lowered patients' VAS for pain and global disease activity, although there was also a reduction in parameters reflecting inflammation, such as CRP, PLT, swollen joints count and BSA.

There is one prior study which has prospectively studied the effects of weight loss in patients with PsA and obesity or overweight starting treatment with a TNF-inhibitor. After 6 months treatment, the patients with a successful weight loss $(\geq 5 \%)$ had a higher rate of achieving MDA than those without a successful weight loss (MDA $50 \%$ vs $23 \% ; p<0.001$ ) [17]. The patients had higher disease activity at baseline than in the present study, but the weight loss, which was achieved by a hypocaloric diet, was lower. One earlier randomized trial studied the effects of low-energy diet (LED) treatment $(800-1000 \mathrm{kcal} /$ day) compared with an ordinary healthy all-round diet in patients with psoriasis and obesity (30 vs. 30$)$ and reported improvement of DLQI and cardiovascular risk profile in the LED arm, but only a trend towards improvement of Psoriasis Area and Severity Index (PASI) after 16 weeks. The weight loss was however correlated with the 

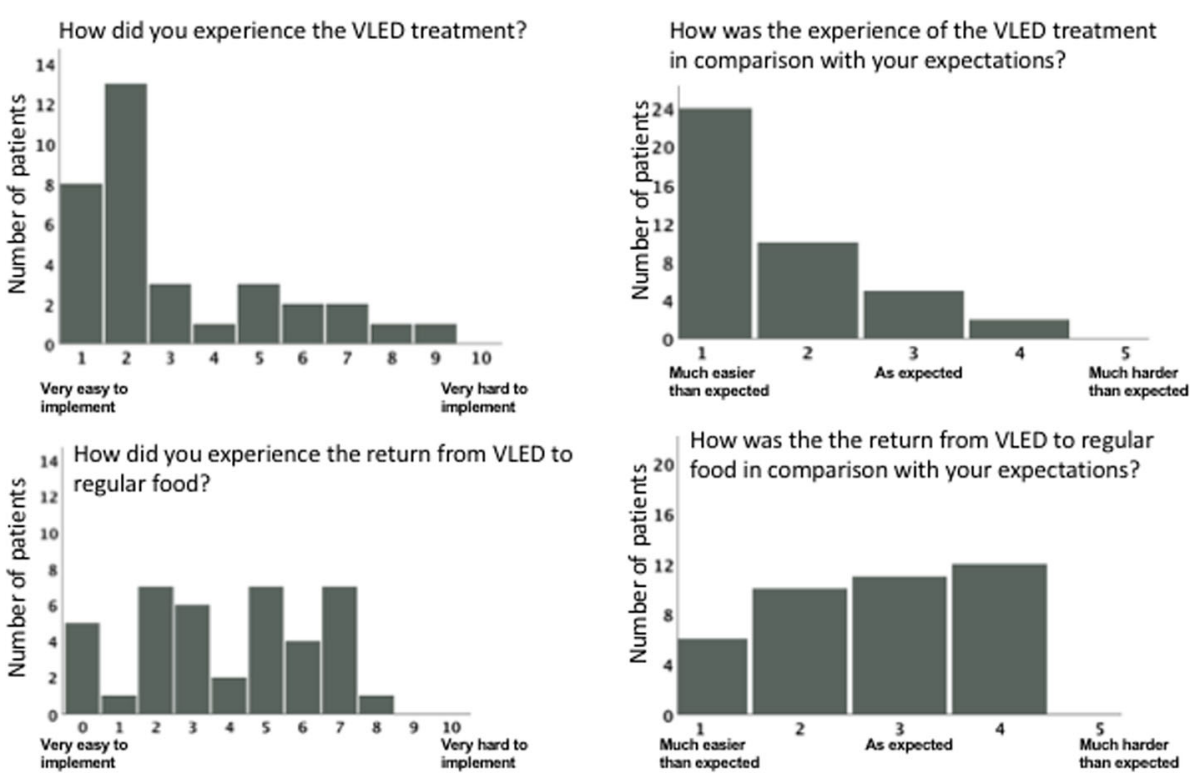

Fig. 3 The patients' experience of the very low energy diet (VLED) treatment and the transition from VLED to normal food

reduction of PASI. The beneficial effects were sustained at 64 weeks follow-up [51, 52]. Positive effects on psoriasis have also been reported retrospectively by patients after bariatric surgery in earlier studies [53, 54].

There are some limitations of the study. First, the present study lacks a control group. The success of the weight loss treatment is reliant on the patients' determination to follow the given instructions and refrain from intake of energy-containing foods and beverages other than the VLED and non-caloric beverages during the initial strict period of $12-16$ weeks. To be effective, VLED treatment must be based on the patients' active decision and randomization between VLED and care-as-usual was therefore considered unsuitable. Second, no blinding of the assessors was made. Third, a high disease activity was not an inclusion criterion of the study, which may have affected the results. In fact, 29\% of the patients had already MDA at baseline. Nevertheless, the study was able to show significant association between weight loss and reduced disease activity. Fourth, no documentation of the side effects (obstipation, freezing, loss of hair and hypotension) was done; hence, no exact data on the occurrence can be presented. No serious adverse event occurred however during the study. Fifth, the study was relatively short in duration, and it is indeed a great challenge to achieve long-term weight loss. The patients will however be followed during 24 months.

Strengths of the present study are the prospective design and the powerful intervention that resulted in a substantial weight loss due to excellent adherence to the dietary regime. The study demonstrates that adding a weight loss treatment to the conventional pharmacologic treatment in patients with PsA and obesity may lead to benefits including lowering of several measures of disease activity along with the weight reduction.

\section{Conclusions}

Weight loss treatment with VLED in patients with PsA and obesity was associated with significant improvement of disease activity in joints, entheses and skin at 6 months follow-up. A larger weight loss resulted in more improvement in a dose-response manner. The treatment was effective, safe and well tolerated. In addition, we could demonstrate association between higher BMI and increased disease activity at baseline. The patients will be followed during 24 months to study long-term treatment effects. The study supports the hypothesis that obesity is involved in the pathophysiology of PsA.

\section{Additional file}

Additional file 1: Table S1. Disease activity and function before and after weight loss treatment in the 29 patients with PSA who did not have minimal disease activity at baseline. (DOCX 16 kb)

\section{Abbreviations}

ACR: American College of Rheumatology; BMI: Body mass index; BSA: Body surface area; CASPAR: Classification for Psoriatic Arthritis; CRP: C-reactive protein; cs/b DMARD: Conventional synthetic/biologic disease modifying anti-rheumatic drug; CV: Cardiovascular; DAPSA: Disease Activity in PSoriatic Arthritis; DAS28CRP: Disease Activity Score using 28 joint counts based on CRP; DLQI: Dermatology Life Quality Index; ESR: Erythrocyte sedimentation rate; HAQ: Health Assessment Questionnaire; Hb: Haemoglobin;

IL: Interleukin; IQR: Interquartile range; MDA: Minimal disease activity; MetS: Metabolic syndrome; NSAID: Non-steroidal anti-inflammatory drug; PLT: Platelet count; PSA: Psoriatic arthritis; PsARC: Psoriatic Arthritis Response 
Criteria; $r_{s}$ : Spearman's correlation; TNFi: Tumour necrosis factor inhibitor; TNFa: Tumour necrosis factor a; VAS: Visual analogue scale; VLED: Very low energy diet; WAT: White adipose tissue; WBC: White blood cell count

\section{Acknowledgements}

We wish to thank all the patients who participated in the study. We also wish to thank Anneli Lund and Marie-Louise Andersson at the Clinical Rheumatology Research Center at Sahlgrenska University Hospital and the personnel at the Obesity Unit at Sahlgrenska University Hospital.

\section{Funding}

This work was supported by grants from the Swedish state under the agreement between the Swedish Government and the county councils, the ALF-agreement (ALFGBG-825511), the Health and Medical Care Executive Board of the Västra Götaland, the Gothenburg Society of Medicine, Inger Bendix foundation for medical research, Rune and Ulla Amlövs foundation for Rheumatology Research, Stiftelsen Psoriasisfonden and the Swedish Rheumatology Association research grant in collaboration with Roche.

\section{Availability of data and materials}

The datasets analyzed during the current study are available from the corresponding author on reasonable request.

\section{Authors' contributions}

EK was responsible for the study design, recruitment of patients, rheumatologic evaluations, data collection, statistical analyses and drafting of the article. AB participated in the study design, recruitment and examination of patients, collection, analysis and interpretation of data. SF participated in recruitment and examination of patients, weight loss treatment and followup, collection and interpretation of data. MH participated in the recruitment and rheumatologic evaluation of the patients and collection of data. $L J$ participated in the study design, analysis and interpretation of data. HF participated in the study design, analysis and interpretation of data. HC participated the study design, analysis and interpretation of data. BE participated in the study design, recruitment and examination of patients, collection and interpretation of data and was responsible for the weight loss treatment and follow-up. IL participated in the study design, recruitment and examination of patients, collection and interpretation of data and was responsible for the weight loss treatment and follow-up. All authors have critically reviewed the manuscript, approved the final version to be published and agreed to be accountable for all aspects of the work.

\section{Ethics approval and consent to participate}

The study was approved by the Regional Ethics Committee in Gothenburg and carried out in accordance with the Helsinki declaration. All participants gave their written informed consent.

\section{Consent for publication}

Not applicable

\section{Competing interests}

The authors declare that they have no financial or nonfinancial competing interests. The patients were able to buy the VLED at a reduced price from Cambridge Weight Plan Limited, Solna, Sweden.

\section{Publisher's Note}

Springer Nature remains neutral with regard to jurisdictional claims in published maps and institutional affiliations.

\footnotetext{
Author details

'Department of Rheumatology and Inflammation Research, Sahlgrenska Academy at the University of Gothenburg, Gothenburg, Sweden. ${ }^{2}$ Institute of Neuroscience and Physiology, Section of Health and Rehabilitation, Physiotherapy, Sahlgrenska Academy at the University of Gothenburg, Gothenburg, Sweden. ${ }^{3}$ Department of Gastroenterology and Hepatology, Sahlgrenska University Hospital, Gothenburg, Institute of Medicine, Sahlgrenska Academy at University of Gothenburg, Gothenburg, Sweden. ${ }^{4}$ Department of Rheumatology, Hospital of Borås, Borås, Sweden. ${ }^{5}$ Department of Public Health and Clinical Medicine, Rheumatology, Umeå University, Umeå, Sweden. ${ }^{6}$ Department of Medicine, Institute of Medicine,
}

Sahlgrenska University Hospital, University of Gothenburg, Gothenburg, Sweden.

Received: 16 September 2018 Accepted: 2 January 2019 Published online: 11 January 2019

\section{References}

1. Ritchlin CT, Colbert RA, Gladman DD. Psoriatic arthritis. N Engl J Med. 2017; 376(21):2095-6.

2. Labitigan M, Bahce-Altuntas A, Kremer JM, Reed G, Greenberg JD, Jordan N, Putterman C, Broder A. Higher rates and clustering of abnormal lipids, obesity, and diabetes mellitus in psoriatic arthritis compared with rheumatoid arthritis. Arthritis Care Res (Hoboken). 2014;66(4):600-7.

3. Haroon M, Gallagher P, Heffernan E, FitzGerald O. High prevalence of metabolic syndrome and of insulin resistance in psoriatic arthritis is associated with the severity of underlying disease. J Rheumatol. 2014;41(7): 1357-65.

4. Bostoen J, Van Praet L, Brochez L, Mielants H, Lambert J. A cross-sectional study on the prevalence of metabolic syndrome in psoriasis compared to psoriatic arthritis. J Eur Acad Dermatol Venereol. 2014;28(4):507-11.

5. Eder L, Harvey P, Chandran V, Rosen CF, Dutz J, Elder JT, Rahman P, Ritchlin $C T$, Rohekar S, Hayday R, et al. Gaps in diagnosis and treatment of cardiovascular risk factors in patients with psoriatic disease: an international multicenter study. J Rheumatol. 2018;45(3):378-84.

6. Li W, Han J, Qureshi AA. Obesity and risk of incident psoriatic arthritis in US women. Ann Rheum Dis. 2012;71(8):1267-72.

7. Eder L, Thavaneswaran A, Chandran V, Cook RJ, Gladman DD. Obesity is associated with a lower probability of achieving sustained minimal disease activity state among patients with psoriatic arthritis. Ann Rheum Dis. 2015; 74(5):813-7.

8. Versini M, Jeandel PY, Rosenthal E, Shoenfeld Y. Obesity in autoimmune diseases: not a passive bystander. Autoimmun Rev. 2014;13(9):981-1000.

9. Setty AR, Curhan G, Choi HK. Obesity, waist circumference, weight change, and the risk of psoriasis in women: nurses' health study II. Arch Intern Med. 2007:167(15):1670-5.

10. Galindez E, Carmona L. Is obesity in psoriatic arthritis associated with a poorer therapeutic response and more adverse effects of treatment with an anchor drug? Reumatol Clin. 2016;12(6):307-12.

11. Jamnitski A, Symmons D, Peters MJ, Sattar N, Mclnnes I, Nurmohamed MT. Cardiovascular comorbidities in patients with psoriatic arthritis: a systematic review. Ann Rheum Dis. 2013;72(2):211-6.

12. Bengtsson K, Forsblad-d'Elia H, Lie E, Klingberg E, Dehlin M, Exarchou S, Lindstrom U, Askling J, Jacobsson LTH. Are ankylosing spondylitis, psoriatic arthritis and undifferentiated spondyloarthritis associated with an increased risk of cardiovascular events? A prospective nationwide population-based cohort study. Arthritis Res Ther. 2017;19(1):102.

13. Bengtsson K, Forsblad-d'Elia H, Lie E, Klingberg E, Dehlin M, Exarchou S, Lindström U, Askling J, Jacobsson LTH. Risk of cardiac rhythm disturbances and aortic regurgitation in different spondyloarthritis subtypes in comparison with general population: a register-based study from Sweden. Ann Rheum Dis. 2018;77(4):541-548. https://doi.org/10.1136/annrheumdis2017-212189.

14. Eder L, Chandran V, Gladman DD. The Framingham risk score underestimates the extent of subclinical atherosclerosis in patients with psoriatic disease. Ann Rheum Dis. 2014;73(11):1990-6.

15. Eder L, Jayakar J, Shanmugarajah S, Thavaneswaran A, Pereira D, Chandran $V$, Rosen CF, Gladman DD. The burden of carotid artery plaques is higher in patients with psoriatic arthritis compared with those with psoriasis alone. Ann Rheum Dis. 2013;72(5):715-20.

16. Eder L, Thavaneswaran A, Chandran V, Cook R, Gladman DD. Increased burden of inflammation over time is associated with the extent of atherosclerotic plaques in patients with psoriatic arthritis. Ann Rheum Dis. 2015;74(10):1830-5. https://doi.org/10.1136/annrheumdis-2014-205267.

17. Di Minno MN, Peluso R, lervolino S, Russolillo A, Lupoli R, Scarpa R. Weight loss and achievement of minimal disease activity in patients with psoriatic arthritis starting treatment with tumour necrosis factor alpha blockers. Ann Rheum Dis. 2014;73(6):1157-62.

18. Taylor W, Gladman D, Helliwell P, Marchesoni A, Mease P, Mielants H, Group CS. Classification criteria for psoriatic arthritis: development of new criteria from a large international study. Arthritis Rheum. 2006;54(8):2665-73. 
19. Mustajoki P, Pekkarinen T. Very low energy diets in the treatment of obesity. Obes Rev. 2001;2(1):61-72.

20. Lean M, Brosnahan N, McLoone P, McCombie L, Higgs AB, Ross H, Mackenzie M, Grieve E, Finer N, Reckless J, et al. Feasibility and indicative results from a 12-month low-energy liquid diet treatment and maintenance programme for severe obesity. Br J Gen Pract. 2013:63(607):e115-24.

21. Healy PJ, Helliwell PS. Measuring clinical enthesitis in psoriatic arthritis: assessment of existing measures and development of an instrument specific to psoriatic arthritis. Arthritis Rheum. 2008:59(5):686-91.

22. Bozek A, Reich $\mathrm{A}$. The reliability of three psoriasis assessment tools: psoriasis area and severity index, body surface area and physician global assessment. Adv Clin Exp Med. 2017;26(5):851-6.

23. Finlay AY, Khan GK. Dermatology Life Quality Index (DLQI)--a simple practical measure for routine clinical use. Clin Exp Dermatol. 1994;19(3): 210-6.

24. Fries JF, Spitz P, Kraines RG, Holman HR. Measurement of patient outcome in arthritis. Arthritis Rheum. 1980;23(2):137-45.

25. Schoels M, Aletaha D, Funovits J, Kavanaugh A, Baker D, Smolen JS. Application of the DAREA/DAPSA score for assessment of disease activity in psoriatic arthritis. Ann Rheum Dis. 2010;69(8):1441-7.

26. Prevoo ML, van 't Hof MA, Kuper $H H$, van Leeuwen $M A$, van de Putte $L B$, van Riel PL. Modified disease activity scores that include twenty-eight-joint counts. Development and validation in a prospective longitudinal study of patients with rheumatoid arthritis. Arthritis Rheum. 1995;38(1):44-8.

27. Coates LC, Fransen J, Helliwell PS. Defining minimal disease activity in psoriatic arthritis: a proposed objective target for treatment. Ann Rheum Dis. 2010;69(1):48-53.

28. Clegg DO, Reda DJ, Weisman MH, Blackburn WD, Cush JJ, Cannon GW, Mahowald ML, Schumacher HR Jr, Taylor T, Budiman-Mak E, et al. Comparison of sulfasalazine and placebo in the treatment of ankylosing spondylitis. A Department of Veterans Affairs Cooperative Study. Arthritis Rheum. 1996;39(12):2004-12.

29. Fransen J, Antoni C, Mease PJ, Uter W, Kavanaugh A, Kalden JR, Van Riel PL. Performance of response criteria for assessing peripheral arthritis in patients with psoriatic arthritis: analysis of data from randomised controlled trials of two tumour necrosis factor inhibitors. Ann Rheum Dis. 2006;65(10):1373-8.

30. Felson DT, Anderson JJ, Boers M, Bombardier C, Furst D, Goldsmith C, Katz LM, Lightfoot R Jr, Paulus H, Strand V, et al. American College of Rheumatology. Preliminary definition of improvement in rheumatoid arthritis. Arthritis Rheum. 1995;38(6):727-35.

31. Mease PJ, Kivitz AJ, Burch FX, Siegel EL, Cohen SB, Ory P, Salonen D, Rubenstein J, Sharp JT, Tsuji W. Etanercept treatment of psoriatic arthritis: safety, efficacy, and effect on disease progression. Arthritis Rheum. 2004; 50(7):2264-72

32. Antoni C, Krueger GG, de Vlam K, Birbara C, Beutler A, Guzzo C, Zhou B, Dooley LT, Kavanaugh A, Investigators IT. Infliximab improves signs and symptoms of psoriatic arthritis: results of the IMPACT 2 trial. Ann Rheum Dis. 2005;64(8):1150-7.

33. Wolk K, Sabat R. Adipokines in psoriasis: an important link between skin inflammation and metabolic alterations. Rev Endocr Metab Disord. 2016; 17(3):305-17.

34. Ivanov S, Merlin J, Lee MKS, Murphy AJ, Guinamard RR. Biology and function of adipose tissue macrophages, dendritic cells and B cells. Atherosclerosis. 2018;271:102-10

35. Chehimi M, Vidal $H$, Eljaafari A. Pathogenic role of IL-17-producing immune cells in obesity, and related inflammatory diseases. J Clin Med. 2017;6(7).

36. Kruglikov IL, Wollina U. Local effects of adipose tissue in psoriasis and psoriatic arthritis. Psoriasis (Auckl). 2017;7:17-25.

37. Eder L, Jayakar J, Pollock R, Pellett F, Thavaneswaran A, Chandran V, Rosen CF, Gladman DD. Serum adipokines in patients with psoriatic arthritis and psoriasis alone and their correlation with disease activity. Ann Rheum Dis. 2013;72(12):1956-61.

38. Xue $Y$, Jiang L, Cheng $Q$, Chen $H, Y u$ Y, Lin Y, Yang $X$, Kong N, Zhu X, Xu X, et al. Adipokines in psoriatic arthritis patients: the correlations with osteoclast precursors and bone erosions. PLoS One. 2012;7(10):e46740.

39. McGonagle DG, Helliwell $P$, Veale D. Enthesitis in psoriatic disease. Dermatology. 2012;225(2):100-9.

40. Scott A, Zwerver J, Grewal N, de Sa A, Alktebi T, Granville DJ, Hart DA. Lipids, adiposity and tendinopathy: is there a mechanistic link? Critical review. Br J Sports Med. 2015;49(15):984-8.
41. Pattison E, Harrison BJ, Griffiths CE, Silman AJ, Bruce IN. Environmental risk factors for the development of psoriatic arthritis: results from a case-control study. Ann Rheum Dis. 2008;67(5):672-6.

42. Eder L, Shanmugarajah S, Thavaneswaran A, Chandran V, Rosen CF, Cook RJ, Gladman DD. The association between smoking and the development of psoriatic arthritis among psoriasis patients. Ann Rheum Dis. 2012;71(2):219-24.

43. Melski JW, Bernhard JD, Stern RS. The Koebner (isomorphic) response in psoriasis. Associations with early age at onset and multiple previous therapies. Arch Dermatol. 1983;119(8):655-9.

44. Jacques $P$, Lambrecht $S$, Verheugen E, Pauwels E, Kollias G, Armaka M, Verhoye M, Van der Linden A, Achten R, Lories RJ, et al. Proof of concept: enthesitis and new bone formation in spondyloarthritis are driven by mechanical strain and stromal cells. Ann Rheum Dis. 2014;73(2):437-45.

45. Arranz LI, Rafecas M, Alegre C. Effects of obesity on function and quality of life in chronic pain conditions. Curr Rheumatol Rep. 2014;16(1):390.

46. Hojgaard P, Glintborg B, Kristensen LE, Gudbjornsson B, Love TJ, Dreyer L. The influence of obesity on response to tumour necrosis factor-alpha inhibitors in psoriatic arthritis: results from the DANBIO and ICEBIO registries. Rheumatology (Oxford). 2016;55(12):2191-9.

47. Longo VD, Mattson MP. Fasting: molecular mechanisms and clinical applications. Cell Metab. 2014;19(2):181-92.

48. Choi IY, Lee C, Longo VD. Nutrition and fasting mimicking diets in the prevention and treatment of autoimmune diseases and immunosenescence. Mol Cell Endocrinol. 2017:455:4-12.

49. Piccio L, Stark JL, Cross AH. Chronic calorie restriction attenuates experimental autoimmune encephalomyelitis. J Leukoc Biol. 2008:84(4):940-8.

50. Frikke-Schmidt H, O'Rourke RW, Lumeng CN, Sandoval DA, Seeley RJ. Does bariatric surgery improve adipose tissue function? Obes Rev. 2016;17(9):795-809.

51. Jensen P, Christensen R, Zachariae C, Geiker NR, Schaadt BK, Stender S, Hansen PR, Astrup A, Skov L. Long-term effects of weight reduction on the severity of psoriasis in a cohort derived from a randomized trial: a prospective observational follow-up study. Am J Clin Nutr. 2016;104(2):259-65.

52. Jensen P, Zachariae C, Christensen R, Geiker NR, Schaadt BK, Stender S, Hansen PR, Astrup A, Skov L. Effect of weight loss on the severity of psoriasis: a randomized clinical study. JAMA Dermatol. 2013;149(7):795-801.

53. Farias MM, Achurra P, Boza C, Vega A, de la Cruz C. Psoriasis following bariatric surgery: clinical evolution and impact on quality of life on 10 patients. Obes Surg. 2012;22(6):877-80.

54. Hossler EW, Wood GC, Still CD, Mowad CM, Maroon MS. The effect of weight loss surgery on the severity of psoriasis. Br J Dermatol. 2013;168(3):660-1.

Ready to submit your research? Choose BMC and benefit from:

- fast, convenient online submission

- thorough peer review by experienced researchers in your field

- rapid publication on acceptance

- support for research data, including large and complex data types

- gold Open Access which fosters wider collaboration and increased citations

- maximum visibility for your research: over $100 \mathrm{M}$ website views per year

At BMC, research is always in progress.

Learn more biomedcentral.com/submissions 